\title{
Por uma nova interpretação das mudanças de paradigma na administração pública
}

\author{
For a new interpretation of the paradigms changes in the public administration
}

Carolina Andion ${ }^{1}$

\begin{abstract}
Resumo
O objetivo deste ensaio é identificar e aprofundar a análise dos paradigmas presentes no campo teórico da administração pública no Brasil. Além de salientar as transformações, trata-se de demonstrar a continuidade paradigmática presente nos estudos do campo em questão. A hipótese central deste texto é de que, embora tenhamos assistido a mudanças paradigmáticas nas duas últimas décadas, o campo da administração pública ainda é dominado assim como nas ciências sociais e na teoria de organizações - por uma concepção funcionalista da ciência. Para demonstrar essa hipótese, utilizamos a seguinte metodologia para construção do argumento epistemológico e consequentemente para elaboração deste ensaio: (i) Partimos de um diálogo com o trabalho de Keinert (1994, 2000), fazendo uma leitura que aponta os limites e busca complementar o mesmo; (ii) examinamos criticamente a trajetória do campo da administração pública no Brasil e as diferentes correntes teóricas que o compõem, com base no modelo de paradigmas construído por Burrell e Morgan (2008); (iii) analisamos então quatro correntes principais que compõem hoje o campo, as quais denominamos de Estadocêntrica; Pluralista; Nova Administração Pública e Novo Serviço Público, caracterizando cada uma delas e identificando os paradigmas nos quais elas estão ancoradas. Para concluir, apresentamos uma síntese, demonstrando o predomínio do paradigma funcionalista no campo da administração pública brasileira e chamando a atenção para a necessidade de se pensar novos caminhos metateóricos pouco explorados (CALDAS, 2007), tendo como inspiração referenciais críticos e interpretativos.
\end{abstract}

Palavras-chave: Correntes Teóricas. Paradigmas. Administração pública.

\begin{abstract}
The objective of this essay is to identify and analyse the theoretical paradigms in the field of public administration in Brazil. The essay demonstrates that there have been no substantial changes in the theoretical paradigms in this field. The central hypothesis is that the field of public administration - as well as social science and organisational theory - is dominated by a functionalist conception of science, although changes in the theoretical paradigms have been perceived in the field in the last two decades. The method used to verify the hypothesis is organised as follows: (i) a discussion of Keinert's work (1994, 2000), pointing out its limitations and offering complements; (ii) a critical examination of the history of the field of public administration in Brazil and its different theories based on the model of paradigms created by Burrell and Morgan (2008); (iii) four main theoretical approaches - "state-centred", pluralist, new public management and new public service - that nowadays compose the field of public administration are analysed and the theoretical paradigm on which each one is based is identified. Finally, a synthesis is presented demonstrating the prevalence of the functionalist paradigm in Brazilian public administration, stressing the need to find new and less-explored meta-theoretical ways (CALDAS, 2007), inspired by critical and interpretative references.
\end{abstract}

Keywords: Theoretical currents. Paradigms. Public administration

Artigo submetido em 18 de novembro de 2011 e aceito para publicação em 23 de janeiro de 2012.

1 Professora do Departamento de Administração Pública no Centro de Ciências da Administração e Socioeconômicas (ESAG) da Universidade do Estado de Santa Catarina (UDESC); Líder do Núcleo de Pesquisa e Extensão em Inovações Sociais na Esfera Pública (NISP) e pesquisadora do Centro de Pesquisa e Informação em Economia Pública, Social e Cooperativa (CIRIEC). Endereço: Rua Maestro Manoel Pernes da Silva, n. 30, Santa Mônica, CEP 88035-430, Florianópolis - SC, Brasil. E-mail: andion.esag@gmail.com 


\section{Introdução}

O objetivo deste artigo é abordar os paradigmas presentes no campo teórico da administração pública no Brasil. Mais especificamente, busca-se dialogar com o trabalho de Keinert $(1994,2000)$ que, a partir de uma pesquisa bibliométrica, desenvolve uma periodização da administração pública no Brasil, identificando os paradigmas predominantes em cada época. Primeiramente, a autora identifica o paradigma do Público como Estatal ou Estadocêntrico, predominante desde os anos 1930 até os anos 1980 e marcado pela influência dos autores da administração clássica e por uma visão unicista e tecnicista da ação do Estado. Num segundo momento, a autora identifica o paradigma da Administração Pública como Ciência Política, correspondente ao período de redemocratização nos anos 1980. Este paradigma se caracterizaria por uma aproximação entre as disciplinas administração pública e a ciência política, caracterizando uma visão "militante" da primeira. Por fim, a autora ressalta o paradigma Sociocêntrico, ou seja, o do público como interesse público. Para ela esse seria o paradigma emergente a partir dos anos 1990 que representaria a síntese dos outros dois, tratando de questões políticas e técnicas. Para Keinert (2000, p.188):

O grande desafio que surge com o novo entendimento é de romper com as dicotomias, ou seja, é ilusório pensar que primeiro se refaz o pacto Estado-sociedade, para depois pensar no operacional. O paradigma emergente demanda abordagens integradoras e autossustentáveis.

A leitura apresentada pela autora supracitada é bastante didática e permite uma compreensão contextualizada sobre as diferentes visões a respeito da administração pública que coexistem no campo científico brasileiro. Porém, percebemos que essa interpretação contém algumas lacunas que buscaremos preencher com este texto. Primeiramente, a autora não aprofunda o conceito de paradigma, confundindo a noção de paradigma com algumas abordagens teóricas ou metáforas que são comumente utilizadas nos estudos da Administração Pública. Em segundo lugar, não é feita uma incursão no debate sobre paradigmas nos campos das ciências sociais e mais especificamente dos estudos organizacionais, nos quais essa discussão epistemológica tem avançado muito recentemente. Trata-se da análise paradigmática da administração pública de forma isolada. Finalmente, a divisão paradigmática é realizada mais em função de uma leitura evolucionista, que divide o campo disciplinar em períodos históricos bem distintos, do que de uma análise do campo das ideias e das correntes teóricas predominantes.

Dessa forma, concebemos nesse texto uma leitura diferente e, de certa forma, complementar a de Keinert (2000). Além de mostrar as mudanças de paradigma, buscaremos enfatizar a continuidade paradigmática presente nos estudos da administração pública no Brasil. Nosso pressuposto central é de que, embora tenhamos assistido a mudanças paradigmáticas nas duas últimas décadas, o campo da administração pública ainda é dominado - assim como nas ciências sociais e na teoria de organizações - por uma concepção funcionalista da ciência. Esse predomínio do paradigma funcionalista estaria aprisionando e limitando o desenvolvimento do campo que cresceria em reflexividade e riqueza, se os distintos paradigmas pudessem se reconhecer e dialogar (CALDAS, 2007).

A contribuição desse ensaio se insere no quadro dos trabalhos que buscam aprofundar o debate epistemológico no campo da administração, em particular levantando as possibilidades de diálogo entre esse campo e novas abordagens teóricas e paradigmáticas pouco exploradas (MENEGUETTI, F. K., 2007; CERCHIARO, I.B., AYROSA, E.A.T. e ZOUAIN. D.M., 2009; ALCADIPANI, R. e TURETA, C., 2009; SERVA, DIAS e ALPERSTEDT, 2010). Mais especificamente, no caso desse artigo, trata-se de trazer esse debate para o âmbito da administração pública, buscando refletir sobre os avanços e limites dessa área disciplinar, com vistas a contribuir para uma maior compreensão sobre sua identidade, suas potencialidades e seus limites, enquanto campo científico e também área de formação profissional (COELHO, 2008).

Para explorar o pressuposto central mencionado acima, o caminho metodológico adotado, diferentemente de Keinert, (que faz um estudo empírico), é o da análise teórica, examinando criticamente a trajetória do campo 
no Brasil e as diferentes correntes que o compõem. Para tanto, tomaremos como referência o trabalho de Burrell e Morgan (2008) e Morgan (2007) que se apoiam na célebre definição de Thomas Khun no livro A Estrutura das Revoluções Científicas. Khun (1987) responde às críticas feitas a sua obra original na qual apresenta diferentes significados de paradigma destacando que: "para os nossos propósitos atuais, sugiro 'matriz disciplinar': 'disciplinar', porque se refere a uma posse comum aos praticantes de uma disciplina particular; 'matriz', porque é composta de elementos ordenados de várias espécies; cada um deles exigindo uma determinação mais pormenorizada" (KHUN, 1987, p. 226). Esses elementos seriam as generalizações simbólicas, os exemplos compartilhados, os compromissos (como crenças em determinados modelos) e os valores.

Aprofundando essa definição, Burrell e Morgan (2008) e Morgan (2007) conceituam paradigma como um conjunto de formulações metateóricas sobre as quais é desenhado um quadro de referência que define uma visão de mundo partilhada por uma comunidade de cientistas. Tais formulações referem-se à natureza da ciência (objetiva ou subjetiva); à realidade social (ênfase na regulação ou na mudança social) e à natureza humana (determinista ou não determinista). Toda visão de mundo pode incluir diversas correntes de pensamento. Morgan vai então identificar, com base nas ciências sociais, quatro paradigmas básicos presentes no campo dos estudos organizacionais: o funcionalista, o interpretativo, o humanista radical e o estruturalista radical. Esses paradigmas são caracterizados e classificados pelo autor, conforme quadro 1 a seguir e serão explorados no decorrer desse texto.

\section{Correntes Teóricas e Continuidade Paradigmática na Administração Pública Brasileira}

A administração pública, enquanto disciplina, pode ser definida como um campo de estudos interdisciplinar que captura as tensões entre uma orientação racional instrumental (voltada para a ampliação da eficácia e da eficiência), de um lado, e uma orientação política (que considera as questões dos valores e visa promover interesse público), de outro (GARSON e OVERMAN, 1983; MARSHALL, 1998). Porém, pode-se afirmar que, desde a origem da disciplina, além de predominar uma visão de separação dessas duas orientações, privilegiou-se mais uma orientação racional/instrumental. De fato, o próprio surgimento da administração pública no século XIX com Wilson (1887) parece retirar o foco da centralidade da política para buscar uma maior compreensão de como os governos são administrados (DENHARDT, 2011) ${ }^{2}$. Os grandes ideais dos clássicos no que se refere ao bom Estado, de Aristóteles à Rousseau, vão então progressivamente perdendo espaço para a ideia de um Estado eficiente.

2 Nota-se que atualmente alguns autores interpretam que o trabalho de Wilson (1887) levava em conta alguns aspectos da dimensão política na administração pública. Ver por exemplo COOK, B. J. Woodrow Wilson's Ideas about Local Government Reform: a Regime Perspective on the New Push for Citizen Engagement in Public Administration. Administration and Society, v. 39, p. 294-314, 2007. 
Quadro 1

Paradigmas, metáforas e correntes no campo dos estudos organizacionais SOCIOLOGIA DA MUDANÇA RADICAL

\section{PARADIGMA DO HUMANISMO RADICAL}

Características: busca desenvolver uma sociologia da mudança radical. Enfatiza os fenômenos da alienação e da falsa consciência,

Correntes nas ciências sociais e nos estudos organizacionais: fenomenologia, hermenêutica, etnometodologia e interacionismo simbólico

Metáforas: Texto, jogos de linguagem

Características: busca compreender o mundo como ele é. Coloca ênfase na compreensão da realidade social, de forma a entender a sua natureza, considerando a subjetividade. Para este paradigma, o mundo social é criado pelos indivíduos e por isso é importante entender a essência da subjetividade do mundo.

\section{PARADIGMA DO ESTRUTURALISMO RADICAL}

Características: enfatiza a mudança estrutural da sociedade. Defende o fato de que a mudança radical deve ocorrer na natureza e na estrutura da sociedade contemporânea. Focaliza a análise das estruturas de poder e de classe.

Correntes nas ciências sociais e nos estudos organizacionais: teorias críticas inspiradas no marxismo e no estruturalismo.

Metáfora: Arena política

\section{PARADIGMA FUNCIONALISTA}

\section{SOCIOLOGIA DA REGULAÇÃO}

Fonte: Morgan 2007 ; Burrell e Morgan 2008.
Características: explica o mundo social da mesma forma que o natural, buscando produzir conhecimento científico útil. Enfatiza a manutenção do status quo: equilíbrio, integração social, ordem, estabilidade. Para o paradigma funcionalista a sociedade tem existência concreta. Predomina neste paradigma uma concepção sistêmica e sincrônica do mundo social orientada para consecução de objetivos.

Correntes nas ciências sociais e nos estudos organizacionais: administração clássica, burocracia e teoria de sistemas.

Metáforas: Máquina, organismo, cultura
A 
Percebe-se que essa tendência permanece com o fortalecimento da administração pública enquanto disciplina no Brasil, e isso se expressa nas diferentes correntes que vão tomando forma ao longo do tempo no campo, como demonstraremos abaixo.

\section{Corrente Estadocêntrica: administração pública como ciência jurídica e ciência administrativa}

Esta corrente é uma das mais influentes no campo da administração pública no Brasil. Seu predomínio se estende desde os primórdios da disciplina até a sua consolidação, período que corresponde do final do século XIX até final dos anos 1970, o qual pode ser dividido em três momentos principais. Num primeiro momento, antes do surgimento da administração pública enquanto disciplina no país, as questões referentes à área estavam principalmente atreladas às ciências jurídicas (KEINERT, 2000). Neste momento, o direito administrativo e a administração pública estavam muito próximos e praticamente se equivaliam.

O segundo momento, de 1930 a 1950, caracteriza-se pelo surgimento da administração pública, enquanto disciplina, no ciclo político do Estado Novo. Neste período destaca-se o Departamento Administrativo do Serviço Público (DASP) como lócus principal de sua difusão. O objetivo formal era então a estruturação de uma administração pública meritocrática e profissionalizada (GAETANI, 1999), visando formar as bases do Estado do Bem Estar no Brasil, nos moldes dos países desenvolvidos. No campo teórico, há uma forte influência da literatura norte-americana, especialmente da progressive public administration. A orientação racional instrumental predomina, com uma preocupação voltada para a questão da eficiência na gestão. Destaca-se neste período a influência dos trabalhos da administração científica de Taylor e da teoria da burocracia de Weber, além dos pioneiros da administração pública americana, dentre eles Gulick (1937) e White (1948), os quais focalizavam o estudo dos processos e da estrutura nas organizações públicas (DENHARDT, 2011).

Num terceiro momento, a partir dos anos 1950 até o final dos anos 1970, há uma consolidação da disciplina da administração pública no país e sua internacionalização com a ampliação da cooperação, especialmente com os EUA (GAETANI, 1999). É criada a Escola Brasileira de Administração Pública, em 1952, sob os auspícios da ONU. Amplia-se a formação dos professores em escolas americanas e o número de publicações na área. No campo das políticas públicas, o papel do Estado se fortalece enquanto promotor de desenvolvimento. O planejamento e a ação do Estado são promovidos de forma centralizada, com uma visão unificadora e tecnicista (KEINERT, 2000), com base na lógica desenvolvimentista.

Já no campo acadêmico, é importante ressaltar duas influências que serão marcantes neste período para a consolidação do campo da administração pública no Brasil. Por um lado, alguns professores/pesquisadores vão focar seus estudos nos aportes teóricos da administração de empresas, tendo por base uma visão pragmática e experimental que assume força no campo nos EUA nesta época (WALDO, 1948; SIMON, 1957). O interesse nesse caso centra-se nas dinâmicas de construção e operação das organizações públicas, tendo em vista a ampliação de sua eficiência. Outro grupo de professores das recém-criadas escolas brasileiras e formados em Universidades com tradição em administração pública, como a Universidade da South Califórnia (USC), por exemplo, traz para o Brasil o aporte dos estudos humanistas e críticos que também vão ter importante papel no campo nesta época e mais tarde, pois levantam os limites da abordagem racionalista, fazendo uma crítica a esta última (ARGYRIS e SCHON, 1978; RAMOS, 1966 e 1989).

Apesar de abarcar alguns estudos humanistas que foram percussores para o campo, pode-se afirmar que a escola de pensamento Estadocêntrica (KEINERT, 2000) ou da Velha Administração Pública (DENHARDT, 2011) tem como foco principal a ampliação da competência e da racionalidade funcional na administração pública (RAMOS, 1966). Esta escola, apesar de envolver diferentes teorias, pode ser identificada pela partilha de algumas concepções comuns: 
- A visão unitária do Estado, concebido como Estado-Nação e único responsável pelo planejamento, operação e avaliação das políticas públicas, de forma centralizada e de cima para baixo;

- O Estado como interventor e regulador, importante motor do desenvolvimento econômico, junto com o mercado (GAETANI, 1999);

- A organização burocrática como tipo ideal com ênfase na hierarquização, na impessoalidade, na neutralidade e na competência técnica (WEBER, 1964 e 1970);

- Distanciamento entre técnica e política na administração pública e separação entre racionalidade funcional e substancial. A ação administrativa é aqui entendida essencialmente como ação orientada pela racionalidade com respeito a fins (instrumental) (RAMOS, 1989);

- Administradores públicos são vistos como funcionários responsáveis por implementar políticas e programas, e por garantir a prática dos princípios burocráticos e da administração científica, enquanto aplicáveis à área pública.

Nos anos 1980, chamados de década perdida, o Estado brasileiro entra em crise, assim como a administração pública (GAETANI, 1999). Muitos são os fatores que vão contribuir para isso. No âmbito externo, ressaltam-se a crise do modelo Fordista ${ }^{3}$ e a emergência de uma agenda internacional neoliberal que diminui a soberania dos Estados Nação, sobretudo nos países dependentes que tinham que cumprir as determinações da fórmula de ajuste estrutural. No âmbito interno, destacam-se a crise fiscal e econômica sem precedentes enfrentada pelo país e a crise de legitimidade do próprio Estado, com o fim da ditadura. Todos esses fatores vão confluir num movimento de transição da administração pública brasileira. Num primeiro momento, esse movimento se traduz numa forte crise da administração pública, inclusive com fechamento de alguns cursos e a perda de crédito por parte da profissão (GAETANI, 1999). Porém, num segundo momento, esse cenário de crise vai abrir novas possibilidades de "recomposição" do campo da administração pública, trazendo à tona novas matrizes de pensamento que serão examinadas a seguir.

\section{Corrente Pluralista: administração pública como campo político}

Vários são os autores que afirmam que - com a abertura democrática, os avanços promovidos pela Constituição de 1988 e a ampliação da mobilização social - percebe-se, a partir do final dos anos 1980, um interesse renovado pelo diálogo entre os campos da administração pública e da ciência política (GAETANI, 1999; KEINERT, 2000; PAES DE PAULA, 2005). Há uma proliferação de estudos que passam a se preocupar com a participação dos atores sociais na definição das agendas políticas e na ampliação do controle social. A política pública passa a ser vista não apenas como resultado de um processo de planejamento centralizado e tecnicista, mas de um processo político e incremental, envolvendo múltiplos atores, como demonstra o percussor trabalho de Lindblom (1959). O Estado deixa de ser visto apenas como sinônimo de aparelho governamental e é interpretado como um espaço de luta entre as diferentes classes sociais (POULANTZAS, 1977 e 1981) ou ainda como uma arena, na qual os diferentes grupos de interesse se encontram.

${ }^{3}$ O Modelo Fordista é aqui entendido como um modelo de desenvolvimento que tem como pilares: um modo de produção taylorista, atrelado à mecanização, caracterizado pela distinção entre aqueles que pensam e aqueles que planejam; um modo de acumulação de riquezas baseado na distribuição dos excedentes pelo capitalista, por meio de aumento de renda dos trabalhadores, além dos direitos trabalhistas, permitindo a formação de uma sociedade salarial e um modelo de intervenção e estatal, chamado de Bem Estar Social, que servia de suporte ao mercado no amparo àqueles que estivessem fora do círculo virtuoso do compromisso Fordista (Lipietz, 1991). 
Mais tarde, nos anos 1990, há uma ampliação dos estudos que se interessam nas dinâmicas da descentralização e da municipalização (ARRETCHE, 1999; FARAH e BARBOZA, 2001). Além disso, destaca-se um maior diálogo da administração pública com as demais ciências sociais, dando espaço para estudos mais críticos no campo. Em particular, podemos citar o diálogo com trabalhos no campo da sociologia política sobre as temáticas dos movimentos sociais (SCHERER-WARREN e KRISCHKE, 1987), da redemocratização (SOUSA SANTOS, 2002), da mobilização social e novo papel político que assume a sociedade civil no Brasil (TELLES, 1987).

Cabe ressaltar que, nos campos disciplinares da ciência política e da sociologia política, foi também relevante neste período a influência do trabalho de Marx e de outros autores influenciados por sua obra (tais como GRAMSCI, 1971; POULANTZAS, 1977 e 1981; OFFE, 1985), em particular no âmbito dos estudos que tinham como objeto a sociedade civil, os movimentos sociais e a sua relação com o Estado (GOHN, 2011). Entretanto, no campo da administração pública, assim como no da administração em geral, esse diálogo foi muito restrito e tênue, não permitindo afirmar que a "corrente marxista" tenha se configurado uma corrente propriamente dita no campo da administração pública no Brasil, embora alguns autores que tiveram influência no campo dos estudos organizacionais tenham se inspirado nos ideais marxistas como Mauricio Tragtenberg, por exemplo, cujo trabalho é definido por Paes de Paula (2008, p. 949) como pertencente à corrente de um "marxismo anarquizante".

Em suma, o principal mérito dos estudos da corrente Pluralista foi trazer à tona a importância da sociedade civil enquanto ator político, dando ênfase a uma visão crítica no âmbito da administração pública brasileira que torna-se mais permeável à participação popular (PAES DE PAULA, 2005). Por outro lado, a crítica que se faz a esta corrente é a de que um pluralismo radical pode levar, no limite, a uma postura anti-institucional. Neste caso, como afirma Nogueira (2005), a sociedade civil poderia ser vista como o espaço por excelência de política, enfraquecendo o próprio Estado e a democracia representativa. Por isso, esse autor defende a importância do diálogo entre democracia representativa e participativa.

Ao mesmo tempo em que ocorre a abertura democrática e as primeiras experiências formais e informais de uma gestão pública mais participativa nos anos 1990 (conselhos, fóruns, comissões de planejamento, redes, etc.), começam a chegar ao país as propostas da Nova Administração Pública. Tais propostas vão promover uma renovação do campo, por meio da tentativa de aplicação da lógica de mercado e dos princípios e práticas empresariais nas organizações públicas. Esse fenômeno será denominado por Dagnino (2002) de "confluência perversa", pois nos dois casos busca-se uma sociedade civil ativa, porém com propósitos distintos: no primeiro caso, a sociedade civil coloca-se como sujeito político; já no segundo, esta é vista e age como um agente prestador de serviços públicos, em complemento ao Estado.

\section{Nova Administração Pública: administração pública como ciência do gerenciamento}

A Nova Administração Pública (NAP) pode ser interpretada como um movimento de resposta à crise do Estado do Bem Estar. Porém, é importante ressaltar que esta crise não se dá de forma natural, por acaso, ou apenas a partir de causas internas ao próprio Estado (ineficiência, falta de eficácia e efetividade) como comumente costuma-se afirmar. Ela está atrelada à crise do próprio modelo de desenvolvimento Fordista que ocorre, principalmente a partir do final dos anos 1970 (LIPIETZ, 1991). Para fazer face a tal crise, emergem nas últimas três décadas um conjunto de abordagens que visam aplicar os princípios do mercado e a lógica empresarial na esfera da administração pública em vários países do mundo (DENHARDT, 2011). O Movimento da NAP caracteriza-se, por um lado, por ser um modelo normativo, formado por um conjunto de abordagens teóricas que se complementam, permitindo uma compreensão da esfera pública e seu funcionamento, a partir dos princípios mercadológicos. 
Por outro lado, a agenda da NAP serviu de referência em muitos países para promoção de reformas com vistas a reestruturar o Estado, substituindo o modelo burocrático (baseado em regras e autoridade) por um modelo gerencial baseado em competição e com foco em resultados (KETTL, 2003). Tais reformas tomavam por base uma receita comum ancorada em uma agenda neoliberal internacional focalizando: a diminuição do aparelho do Estado; a desregulamentação; o controle fiscal; a privatização de empresas públicas e a aplicação de técnicas empresariais no âmbito governamental. Como afirmam Pollit e Bouckaert (2002), alguns países como Austrália, Nova Zelândia e Reino Unido aplicaram essas reformas de maneira mais intensa, liderando o movimento da NAP no mundo ${ }^{4}$.

Mas a NAP não se resume a um conjunto de técnicas. Como demonstram Ferlie et al, 1999, a NAP é composta por uma série de valores e princípios administrativos que configuram diferentes modelos de gestão (voltados para a eficiência, a descentralização e a excelência do serviço público). Na nossa leitura, as diferenças entre esses modelos não são tão prementes como destacam os autores mencionados. Pode-se perceber uma linha comum nas abordagens que formam a NAP, permitindo afirmar a existência de um modelo de gestão coerente, como demonstra Denhardt (2011). Esse modelo se apoia em correntes teóricas tanto dos estudos sobre políticas públicas, quanto da gestão pública que, em seu conjunto, promovem uma renovação e uma verdadeira ruptura no campo da administração pública nas últimas décadas. A seguir, no Quadro 2 apresentamos sinteticamente essas correntes, seus princípios e autores representativos.

Quadro 2

Correntes que formam a Nova Administração Pública

\begin{tabular}{|c|c|c|c|}
\hline CORRENTES & NEOINSTITUCIONALISMO & GERENCIALISMO & BOA GOVERNANÇA \\
\hline $\begin{array}{l}\text { PRINCIPAIS } \\
\text { AUTORES }\end{array}$ & $\begin{array}{l}\text { OSTROM (1986) } \\
\text { WILLIAMSON (1985) } \\
\text { KAUFMAN (1998) }\end{array}$ & $\begin{array}{l}\text { POLLITT (1993) } \\
\text { OSBORN e GAEBLER (1992) } \\
\text { FERLIE et al (1999) } \\
\text { KETTL (2003) }\end{array}$ & $\begin{array}{l}\text { KOOIMAN (1993) } \\
\text { MARCH e OLSEN (1989) }\end{array}$ \\
\hline TEORIAS & $\begin{array}{l}\text { Teoria da Agência } \\
\text { Teoria das Escolhas Públicas } \\
\text { Institucionalismo da Escolha } \\
\text { Racional } \\
\text { Institucionalismo da Economia } \\
\text { Política }\end{array}$ & $\begin{array}{l}\text { Gerencialismo } \\
\text { Neogerencialismo }\end{array}$ & $\begin{array}{l}\text { Governança Corporativa } \\
\text { Teoria dos custos de } \\
\text { transação }\end{array}$ \\
\hline
\end{tabular}

${ }^{4}$ Kettl (2003) distingue as reformas nos países que adotaram mais fielmente os princípios da NAP, seguindo rigorosamente os princípios da economia neoclássica, como a Nova Zelândia e a Inglaterra, e que tiveram como lema fazer os gerentes gerenciar, daquelas reformas que adotaram estratégias mais brandas, visando melhorar o desempenho, como a Austrália, por exemplo. Segundo Kettl, nesses casos trata-se de uma lógica de deixar os gestores públicos gerenciar, concedendo-lhes maior autonomia e flexibilidade e responsabilizando-os pelos resultados, incorporando alguns dos mecanismos de mercado. 


\begin{tabular}{|c|c|c|c|}
\hline FOCO & $\begin{array}{l}\text { Entender as leis que } \\
\text { estruturam a ação dos atores } \\
\text { políticos, de modo a construir } \\
\text { teorias sobre a administração } \\
\text { pública e a política (modelos } \\
\text { gerais), tendo como } \\
\text { inspiração a economia } \\
\text { neoclássica. }\end{array}$ & $\begin{array}{l}\text { Ampliação da performance } \\
\text { dos gestores públicos, por } \\
\text { meio de sua } \\
\text { profissionalização. }\end{array}$ & $\begin{array}{l}\text { Promoção de um estilo } \\
\text { ótimo de ação pública e de } \\
\text { novos arranjos institucionais } \\
\text { na fronteira entre esfera } \\
\text { pública e privada. }\end{array}$ \\
\hline PRINCÍPIOS & $\begin{array}{l}\text { - } \begin{array}{l}\text { Funcionamento de esfera } \\
\text { pública comparada aos } \\
\text { mercados perfeitos. } \\
\text { - } \quad \text { O estado normal da } \\
\text { política é de regularidade } \\
\text { e os atores visam } \\
\text { maximizar seus ganhos } \\
\text { (atores interessados). } \\
\text { - Ênfase na regulação } \\
\text { (ordem), visando limitar } \\
\text { divergências, por meio de } \\
\text { monitoramento dos } \\
\text { agentes pelos principais. } \\
\text { Importância das relações } \\
\text { contratuais (organizações } \\
\text { e mercados como redes } \\
\text { de contratos). } \\
\text { Buscam-se regras } \\
\text { racionais para entender o } \\
\text { comportamento dos } \\
\text { atores políticos. } \\
\text { interesse público } \\
\text { corresponde à soma de }\end{array} \\
\text { interesses privados. }\end{array}$ & 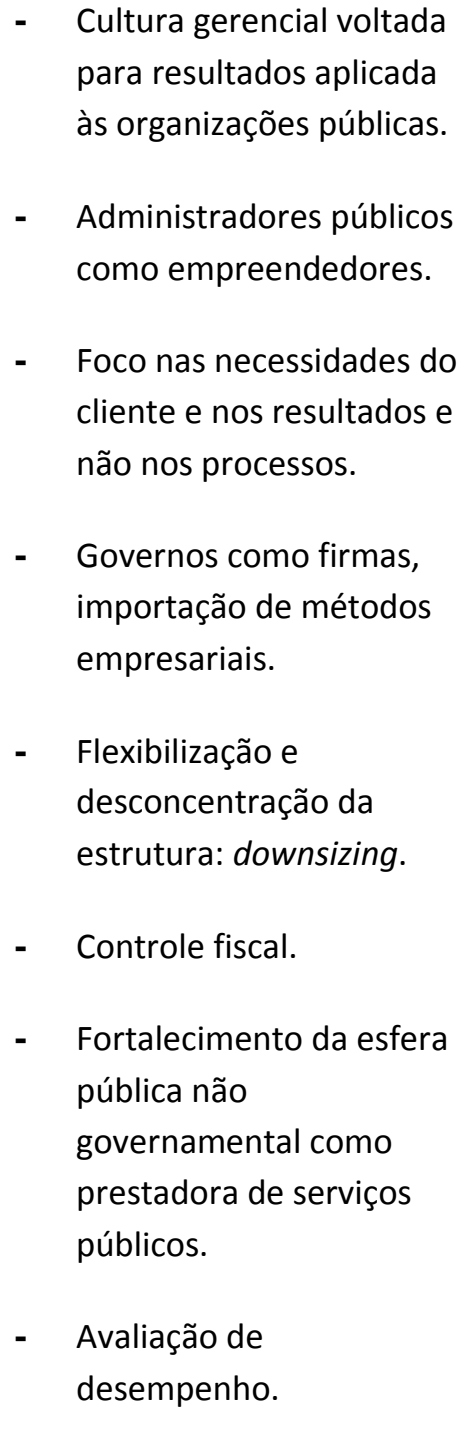 & 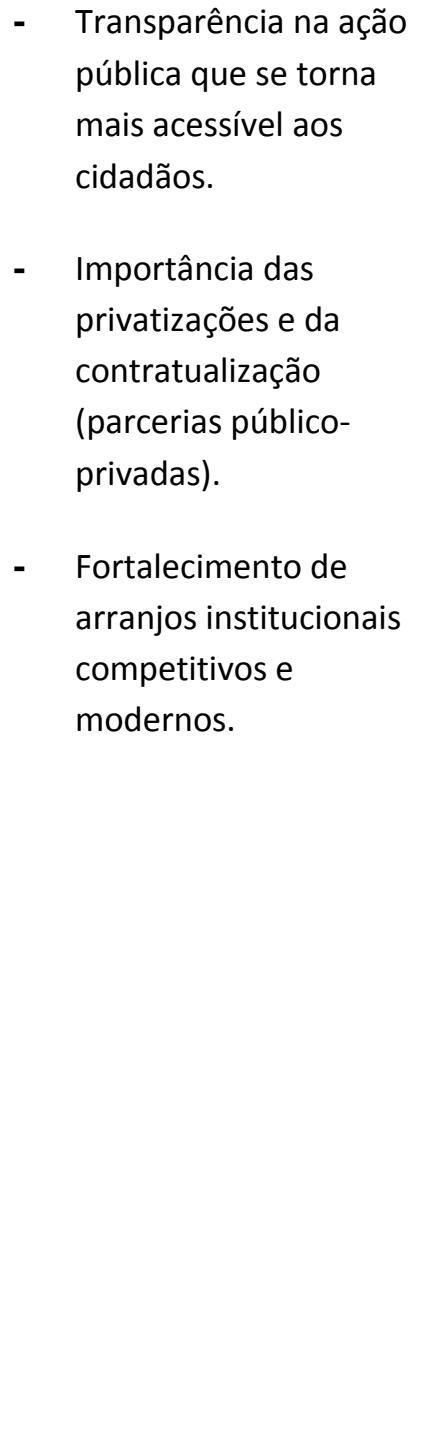 \\
\hline
\end{tabular}

Fonte: Elaborado pela autora com base nas obras citadas.

Sem dúvida, a NAP e seus princípios trouxeram importantes mudanças na administração pública em todo mundo. No Brasil, em específico, a NAP foi a base para a terceira grande Reforma Administrativa implantada pelo então Ministro Bresser Pereira, durante a gestão do Presidente Fernando Henrique Cardoso. 
Segundo Bresser Pereira (2003), a reforma tinha como objetivo reconstruir o Estado brasileiro, por meio de uma ampla reestruturação (com descentralização, privatização e valorização da esfera pública não governamental), do controle fiscal e da implantação de técnicas gerenciais que melhorassem a performance do Estado. Muitos são os autores que mostram que a reforma de 1998 deixou muito a desejar em relação às mudanças propostas (DINIZ, 2001; PAES DE PAULA, 2005; NOGUEIRA, 2005; ABRUCIO, 2007). Essa avaliação não é feita apenas no caso do Brasil, mas se aplica também a outros países que foram percussores na aplicação da NAP (POLLITT e BOUCKAERT, 2002).

Sem nos concentrar em aspectos específicos da crítica feita pelos autores citados acima, o que fugiria aos objetivos deste texto, percebe-se que um dos principais elementos de crítica à NAP consiste em seu viés administrativo e economicista. As propostas feitas pela NAP para responder à crise do Estado desconsideram a dimensão política e institucional das reformas. Estas últimas são colocadas como uma resposta automática e padronizada às exigências da globalização, vendo a adaptação (com base numa agenda neoliberal) como a única saída possível. Essa perspectiva nega a capacidade de reação dos Estados nacionais e os coloca como meros objetos passivos das forças externas, as quais não podem controlar e devem então apenas se submeter (DINIZ, 2001).

Com base na análise dos limites da aplicação da NAP vão emergir, mais recentemente, novas correntes de pensamento que buscam focalizar a importância de revitalizar a ação do Estado e dos gestores públicos para que eles possam servir melhor aos cidadãos e à sociedade (DENHARDT e DENHARDT, 2003; DENHARDT, 2011). Nesta perspectiva importa não apenas melhorar o desempenho do Estado na prestação do serviço público, mas principalmente criar novos padrões de relação entre Estado e sociedade. Recoloca-se a importância das dimensões política e institucional das reformas. É nesse contexto que surge a proposta do Novo Serviço Público.

\section{Corrente do Novo Serviço Público: administração pública como coprodução do bem público}

Um breve exame na recente literatura da administração pública norte-americana (WITHAKER, 1980; BERNIER, BOUCHARD e LÉVESQUE, 2003; DENHARDT e DENHARDT, 2003; DENHARDT, 2011) e europeia (DURAN e THOENIG, 1996; ENJOLRAS, 2008) permite afirmar que os modelos apontados anteriormente não abordam toda a produção intelectual do campo da administração pública nas últimas décadas. A proposta do Novo Serviço Público (NSP), como iremos denominar o conjunto dessas abordagens, surge como um contraponto às correntes Estadocêntrica e da Nova Administração Pública. Como os demais modelos, o NSP consiste de diferentes abordagens teóricas que trazem à tona novos princípios normativos e descritivos para o campo. Segundo Denhardt e Denhardt (2003), o NSP constitui um novo modelo de gestão que tem por base as teorias democráticas e da cidadania (com ênfase na construção do interesse público para além da soma dos interesses individuais); os modelos de comunidade e da sociedade civil (que ressaltam a importância do poder local); além do humanismo organizacional e da teoria do discurso (que dão importância ao diálogo e à mediação entre diferentes agentes que atuam na esfera pública).

Mais do que descrever um modelo coerente e monolítico, o Movimento do NSP nos parece abrir novas vias para compreensão da ação pública na atualidade. Nesse sentido, cabe destacar a abordagem da coprodução do bem público que vê o usuário do serviço público não como cliente ou simples beneficiário. $\mathrm{O}$ cidadão torna-se, nessa perspectiva, protagonista na prestação do serviço público e na promoção da transformação social (WHITAKER, 1980; ALFORD, 2002; BRUDNEY e ENGLAND, 2003; MARSHALL, 2004; COOPER e KATHI, 2005; NADIR, SALM e MENEGASSO, 2007). Neste caso, não há separação entre oferta e demanda de serviço, esses dois campos se sobrepõem. O sucesso de uma política pública aqui não é determinado apenas pela aplicação de leis e normas ou pelo desempenho técnico, ela depende também do envolvimento dos cidadãos nas tomadas de decisão (comportamento cooperativo). Neste sentido, o ajuste mútuo torna-se um elemento muito importante. 
Duran e Thoenig (1996) vão nessa mesma direção chamando atenção para a fluidez, a heterogeneidade e pela fragmentação do poder político no espaço público contemporâneo. Eles mostram que atualmente os atores públicos perdem a sua centralidade e passam a depender cada vez mais de terceiros. Vários atores e instâncias podem intervir sobre o mesmo problema, já que a natureza das questões públicas se torna mais complexa, exigindo cada vez mais uma inteligência transversal. A complexidade dos problemas vai então exigir dos atores a comunicação e a cooperação, para que se construam soluções inovadoras. Neste sentido, a coordenação da ação coletiva desfragmentada emerge como um desafio, cuja solução não é evidente.

Estudos recentes no campo da governança pública (BERNIER, BOUCHARD e LÉVESQUE, 2003; ENJOLRAS, 2008), vêm demonstrando que o que ocorre na atualidade não é o desmantelamento de toda a forma de regulação da ação coletiva, mas o surgimento de novas formas. Os modelos tradicionais de regulação socioeconômica, caracterizados pela centralidade do Estado ou do mercado, convivem com outros modos de condução da ação coletiva (governança comunitária ou em parceria). Desta maneira há um deslocamento das formas tradicionais de governar para modelos de governança compartilhados.

A parceria é outra abordagem possível para um novo modo de regulação. Aqui a questão da governança se coloca como de extrema importância. Unir a ação de atores sociais de diferentes origens é uma condição necessária para a parceria, mas juntar ações individuais não constitui em si a parceria. A parceria requer acordo e investimento de recursos que vão além da partilha de ações. Ela coloca junto atores que têm de obedecer sua própria lógica, mas, ao mesmo tempo, buscar áreas de compatibilidade institucional para ampliar a sua cooperação (BERNIER, BOUCHARD e LÉVESQUE, 2003, p. 329).

Pode-se perceber que a abordagem do Novo Serviço Público coloca novas luzes sobre aspectos pouco tratados pelas outras correntes. Em particular, percebe-se que há re-localização do espaço público na atualidade que se encontra numa zona de tensão permanente entre as esferas pública e privada (o público extrapola o Estatal). Isso pressupõe uma verdadeira ressignificação da ação pública ilustrada por algumas das ideias força tratadas por Denhardt e Denhardt (2003) nos seu livro The New Public Service e também pelos outros autores citados, as quais representariam a essência do NSP:

- O interesse público é o alvo não um sub-produto. $O$ foco dos servidores públicos deve ser a construção de interesses e responsabilidades compartilhadas junto a cidadãos e não a consumidores. Isso exige uma transição de interesses individuais, para interesses coletivos e gerais, o que pressupõe acordos.

- Servir no lugar de guiar. Mais do que pilotar a máquina pública, os gestores públicos devem ser capazes de agir como árbitros e mediadores de ações coletivas. Cada vez mais a legitimação do Estado estará ligada à sua capacidade de agir como um negociador junto aos vários atores (e seus interesses) que agem na cena pública.

- Pensar estrategicamente, agir democraticamente. Políticas e programas públicos podem ser mais efetivos se concebidos e implementados por meio de processos colaborativos (co-produção). Até porque os problemas públicos são muito mais complexos para serem resolvidos apenas pelo Estado.

- O território (não no sentido administrativo), mas como lócus de identidade e de recursos específicos, passa a ser o espaço privilegiado de intervenção pública. O território é construído política e socialmente, em relação a um problema específico.

- Reconhecer que accountability não é simples. Accountability vai muito além da prestação de contas em termos financeiros e de resultado. Torna-se necessário levar em conta as leis, as normas, os valores comunitários e os interesses dos cidadãos. 
- A cidadania deve ser colocada acima do empreendedorismo. $O$ foco excessivo na eficácia pode obscurecer o foco central que é promover o interesse público. Os servidores públicos não são apenas executivos do aparelho do Estado.

No Brasil, percebe-se a influência das ideias do Novo Serviço Público é muito recente e se dá, sobretudo, após a consolidação democrática a partir da segunda metade dos anos 1990. Neste período há uma maior ampliação da descentralização entre as esferas de governo (com a municipalização), ocorre a criação de novos espaços de participação da sociedade civil na esfera pública (por meio de plebiscitos, audiências públicas, conselhos públicos, etc.), surgem novos direitos (como os direitos difusos) e há um reforço à mobilização social (por meio dos novos movimentos sociais e do envolvimento do setor privado nas questões públicas). Todos esses fatores permitem afirmar que nas duas últimas décadas o Brasil vem consolidando pouco a pouco seu compromisso com o regime democrático, gerando um clima favorável a novos arranjos políticos e institucionais. Esse processo reflete-se na ampliação dos estudos que visam compreender os avanços e limites desses novos arranjos institucionais na esfera pública (PAES DE PAULA, 2005; MILANI, 2008).

Porém, como afirmam Nogueira (2005), Diniz (2001) e Abrucio (2007) não houve ainda uma mudança substancial nos padrões de relação entre Estado e sociedade. Ainda permanece um alto grau de centralização de poder no executivo e um isolamento (insulamento burocrático) dos gestores públicos (NUNES, 1997). Percebe-se ainda uma forte influência dos padrões patrimonialistas, principalmente na esfera municipal. Esta esfera ainda caracteriza-se por um baixo poder de implementação das políticas públicas. Os municípios se multiplicaram, a partir de critérios políticos, muitas vezes sem a mínima condição de sustentabilidade. Por outro lado, há uma clara incompletude no processo de constituição de cidadania, resultando em importantes lacunas quanto aos direitos civis (DINIZ, 2001). Há um amplo contingente populacional que ainda se situa totalmente fora da cobertura do Estado no Brasil, demonstrando a incapacidade da administração pública de garantir o princípio da universalidade.

Para superar esses entraves, torna-se necessário explorar a contribuição de novos paradigmas dirigidos não apenas por uma concepção funcionalista. Neste aspecto as pistas lançadas pela matriz de pensamento do Novo Serviço Público podem ser inspiradoras.

\section{Considerações Finais: Examinando de Outra Forma os Paradigmas na Administração Pública Brasileira}

A partir da análise dessas correntes, pode-se concluir o predomínio do paradigma funcionalista cujas concepções embasam os pressupostos das correntes dominantes no campo da administração pública brasileira: a corrente Estadocêntrica e a Nova Administração Pública. Os trabalhos e autores dessas correntes enfatizam uma concepção harmônica e sincrônica dos sistemas sociais, com vistas a conceber um estado de coisas ordenado e regulado (SÉGUIN e CHANLAT, 1992). A ação do Estado e dos gestores públicos é então confundida com a ação administrativa tradicional entendida como "modalidade de ação social, [típica das organizações formais], dotada de racionalidade funcional e que supõe que estejam seus agentes, enquanto a exercem, sob a vigência predominante da ética da responsabilidade" (RAMOS, 1966, p. 47). Os administradores públicos são então avaliados pela sua contribuição para a ampliação do desempenho e para a consecução dos objetivos organizacionais. Neste paradigma, são isoladas as questões subjetivas (ligadas à ética da convicção) e, portanto, os aspectos referentes à política enquanto campo de embate de valores. $\mathrm{O}$ administrador público tem que se manter distante da política, atuando como um "técnico especialista" na visão Estadocêntrica ou como um executivo empreendedor na visão da NAP.

Em ambos os casos, a administração pública é entendida como um instrumento para ampliação da eficiência e eficácia do Estado e deve ser o mais neutra possível (isenta de valores), produzindo princípios e práticas úteis para melhoria do desempenho do sistema (concepção teleológica). Separa-se então política e 
administração e essa passa a ser entendida no mesmo sentido que administração de empresas (COELHO, 2008). Não se busca construir uma perspectiva crítica que produza questionamento, ao contrário impera uma visão integradora, na qual não há espaço para o conflito. Por outro lado, as problemáticas ligadas à historicidade e à contextualização dos fenômenos são também desconsideradas (SÉGUIN e CHANLAT, 1992). A ênfase é o pragmatismo, a partir do diálogo com as ciências "mais objetivas" (como o direito e a economia, por exemplo), no sentido de produzir conhecimento que possa ser aplicado e desse modo seja válido (MORGAN, 2007 e MENEGUETTI, 2007). A visão da NAP, por exemplo, é que a importação dos princípios da economia neoclássica irá produzir uma maior legitimidade e rigor ao campo da administração pública.

O predomínio do paradigma funcionalista na administração pública brasileira tem estimulado uma visão objetivista no campo, com pouco espaço para a historicidade, o conflito e a subjetividade dos atores políticos. Os cidadãos são interpretados na maioria dos casos como "homens organizacionais", cujo papel é se adaptar às regras do sistema, ou como "homens econômicos" que visam maximizar seus ganhos (RAMOS, 1989). Como ressalta esse autor interesse público, neste caso, é muitas vezes tratado como um constructo metafísico que tem utilidade apenas para uso como política cognitiva.

Muito embora essas constatações sejam absolutamente verdadeiras, é importante ressaltar que a concepção funcionalista não é a única que está presente no campo, como acabamos de mostrar anteriormente e sintetizamos no Quadro 3 abaixo. 
Quadro 3

Paradigmas, correntes e teorias no campo dos estudos da administração pública brasileira

SOCIOLOGIA DA MUDANÇA RADICAL

\section{PARADIGMA DO HUMANISMO RADICAL}

Ênfase na mobilização da sociedade civil e na sua atuação enquanto sujeito de mudança social.

CORRENTE PLURALISTA (ESTUDOS CRÍTICOS E HUMANISTAS)

- $\quad$ Teorias sobre os Novos Movimentos Sociais

- Teorias da Democracia Participativa

- Teorias críticas na administração pública

\section{PARADIGMA INTERPRETATIVO}

Ênfase na compreensão da realidade da administração pública, considerando a subjetividade da política (importância dos valores).

\section{CORRENTE DO NOVO SERVIÇO PÚBLICO}

- Teorias da coprodução dos serviços públicos

- Teorias da participação comunitária e da sociedade civil

- Teorias críticas, humanistas e do discurso

- Novas teorias do desenvolvimento (territorial e sustentável)

A

D

E

\section{PARADIGMA DO ESTRUTURALISMO RADICAL}

Ênfase nas relações entre Estado e Sociedade.

Estado como espaço de luta entre as classes sociais.

\section{CORRENTE PLURALISTA \\ (ESTUDOS MARXISTAS E NEOMARXISTAS)}

- Teorias dos Movimentos Sociais

- Teorias sobre o Estado Capitalista

\section{PARADIGMA FUNCIONALISTA}

Ênfase na concepção de leis universais que permitam explicar o funcionamento da administração pública e o comportamento dos atores políticos, com vistas a promover ordem e equilíbrio (regularidades).

\section{CORRENTE ESTADOCÊNTRICA}

- Teoria da administração científica

- Teoria da burocracia

- Progressive Public Administration

- Teorias comportamentais

- Teorias de sistemas

\section{CORRENTE DA NOVA ADMINISTRAÇÃO PÚBLICA}

- Teoria das escolhas públicas

- Teoria da agência

- Neo-institucionalismo das escolhas racionais

- Neo-institucionalismo econômico

- Gerencialismo e Neo-gerencialismo

- Teoria da Boa Governança

Fonte: Elaborado pela autora com base em Morgan (2007) e Morgan e Burrell (2008) e nos outros autores citados. 
As correntes que emergem nas últimas décadas, como a Pluralista e a do Novo Serviço Público vêm lançar novas bases de compreensão da administração pública e reconfigurar a sua identidade enquanto campo científico, a partir do diálogo com outras disciplinas das ciências sociais, como a ciência política, a sociologia política, a geografia e a antropologia. Fazendo isso, elas trazem à tona novos pressupostos epistemológicos, teóricos e metodológicos para o campo, promovendo o seu enriquecimento. Torna-se possível assim pensar outros caminhos metateóricos promissores para além do funcionalismo (CALDAS, 2007).

Tomando como ilustração as teorias citadas neste artigo, observa-se que os paradigmas interpretativo e humanista radical (MORGAN, 2007) têm sido mais explorados nos estudos do campo, especialmente quando nos referimos aos trabalhos mais recentes desenvolvidos tanto no âmbito da corrente Pluralista (ARRETCHE, 1999; FARAH e BARBOZA 2001; SOUSA SANTOS, 2002), quanto na corrente do Novo Serviço Público (PAES DE PAULA, 2005; MILANI, 2008), os quais exploram o momento de transição do papel do Estado, (que perde o monopólio da produção do bem público), e visam compreender o atual contexto de governança ampliada que envolve novos princípios e práticas da administração pública, a exemplo da descentralização, da participação dos cidadãos na coprodução do bem público, dos novos arranjos institucionais, entre outros.

Exercendo uma menor influência, mas também presente, principalmente nos estudos referentes à relação entre Estado e sociedade civil, como citado acima (GOHN, 2011), nota-se também a presença do paradigma do estruturalismo radical. Como autores que se inserem nesse paradigma e que inspiraram trabalhos no campo da administração pública no Brasil pode-se citar a título de ilustração, além do próprio Marx e Gramsci (1971), Poulantzas, (1977, 1981) e Offe (1985).

Pode-se então concluir, com inspiração em Morgan (2007) e Burrell e Morgan (2008) que o campo da administração pública tem a possibilidade objetiva de se desenvolver em termos científicos, se proporcionar um maior reconhecimento dos outros paradigmas (interpretativo, humanista radical e estruturalista radical) e das suas respectivas correntes, proporcionando um diálogo desses com o paradigma dominante. Tal diálogo poderia inclusive contribuir para reforçar cientificamente e construir uma identidade própria para o campo da administração pública brasileira, respondendo também a alguns obstáculos desse campo enquanto área de formação profissional que tem se estruturado muito mais de forma mimética em relação à administração de empresas e na qual ainda impera uma insistente separação entre administração e política (COELHO, 2008), além de uma visão a-crítica e pouco contextualizada em relação à nossa realidade nacional.

Tudo isso implica abrir um maior espaço no campo da administração pública nacional para escolas de pensamento e trabalhos científicos que tenham por base pressupostos não funcionalistas, considerando os referenciais críticos e interpretativos. Pressupõe então uma oxigenação do campo, tornando-o menos mecânico e menos refratário à inovação e à interdisciplinaridade.

Vários são os autores contemporâneos (tais como SÉGUIN; CHANLAT, 1992; SOUSA SANTOS, 1988, 2003; BERTHELOT, 2001) que afirmam que os campos interdisciplinares (como a administração pública) exigem um novo enfoque epistemológico. Este enfoque transcende as dicotomias tradicionais - como sujeito/objeto, subjetividade/objetividade, quantitativo/qualitativo, animado/inanimado, indivíduo/sociedade, ser humano/meio ambiente - que se colocam como intransponíveis na concepção da ciência clássica e que passam a ser vistas como faces da mesma moeda numa perspectiva não dual.

Tal perspectiva implica uma epistemologia sistêmico-complexa que coloque em primeiro plano o desvelamento das relações de interdependência entre os diferentes aspectos da realidade social (MORIN e LE MOIGNE, 1999). Segundo esses autores, a complexidade é assumida como um desafio a ser superado e não como uma solução. Neste sentido, caracteriza-se mais como uma direção a seguir do que como um estado a ser alcançando. 
O desafio consiste, segundo os dois autores supracitados, em tentar religar o que antes estava separado: religar o evento a ser analisado ao contexto; o global ao parcial; o universal ao singular; a ordem à desordem e à organização; o indivíduo à sociedade e ao ecossistema; a coerência lógica à contradição; o observador ao fenômeno observado. Desta forma, considerar a complexidade implica restituir as relações, as interdependências e as solidariedades entre os objetos e seus contextos. Transcender a visão dualista da realidade social, trazendo para o campo uma perspectiva complexa (que não separe, mas inter-relacione as suas dimensões constitutivas) nos parece o grande desafio atual da administração pública enquanto disciplina.

\section{Referências}

ABRUCIO, L. F. Trajetória recente da gestão pública brasileira: um balanço crítico e a renovação da agenda de reformas. Rev. Adm. Pública, Edição Especial Comemorativa, p.67-87, 2007.

ALCADIPANI, R.; TURETA, C. Teoria do ator-rede e estudos críticos em administração: possibilidades de um diálogo. Cad. EBAPE.BR, v.7, n. 3, artigo 2, p. 406-418, 2009.

ALFORD, J. Why do Public-sector clients coproduce? Toward a contingency theory. Administration \& Society, v. 34, n. 1, p. 32-56, março, 2002.

ARGYRIS, C.; SCHON, D. Organizational Learning. Reading: Addison-Wesley, 1978.

ARRETCHE, M. T. S. Políticas Sociais no Brasil: descentralização em um Estado federativo. Revista Brasileira de Ciências Sociais, v. 14, n. 40, p. 11-141, junho, 1999.

BERNIER, L.; BOUCHARD, M.; LÉVESQUE, B. Attending to the general interest: new mechanisms for mediating between the individual, collective and general interest in Québec In CIRIEC Annals of Public and Cooperative economics. Oxford: Blackwell Publishing, v. 74, n. 3, setembro, 2003.

BERTHELOT, J.-M. Épistemologie des Sciences Sociales. Paris: PUF, 2001.

BRUDNey, J.; ENGLAND, R. Toward a definition of the coproduction concept. Public Administration Review, v. 43, n.1, p. 59-65, 2003.

BURRELL, G; MORGAN, G. Sociological Paradigms and Organisational Analysis. Hants: Ashgate, 2008.

CALDAS, M. Paradigmas em estudos organizacionais: uma introdução à série. In CALDAS, M; BERTERO, C. O. Teoria das Organizações. Série RAE Clássicos. São Paulo: FGV/RAE/Atlas, 2007.

CERCHIARO, I.B.; AYROSA, E.A.T; ZOUAIN, D.M. A aplicação de abordagens feministas na pesquisa em administração. Cad. EBAPE.BR, v.7, n. 4, artigo 9, p. 650-664, 2009.

COELHO, F. de S. A problemática atual do ensino de graduação em administração pública no Brasil. Cad. EBAPE.BR, Número Especial, p. 1-21, Agosto, 2008.

COOPER, T. L.; KATHI, P. C. Neighborhood councils and city agencies: a model of collaborative coproduction. National Civic Review, p. 43-53, Spring, 2005.

DAGNINO, E. Sociedade Civil, Espaços Públicos e a Construção Democrática no Brasil: Limites e Possibilidades. In: DAGNINO, E. (Org.). Sociedade Civil e Espaços Públicos no Brasil. Rio de Janeiro: Paz e Terra, 2002.

DENHARDT, J.V.; DENHARDT, R.B. The New Public Service. Serving, not Steering. New York: M.E Sharpe, 2003. 
DENHARDT, R.B. Teorias da Administração Pública. São Paulo: Cengage Learning, 2011.

DINIZ, E. Globalização, Reforma do Estado e Teoria Democrática Contemporânea. São Paulo em Perspectiva, v. 15, n. 4, p. 13-22, 2001.

DURAN, P. ; THOENIG, J-C. L'État et la gestion publique territoriale. In: Revue Française de Science Politique, 46e année, ${ }^{\circ}$ 4, p. 580-623, 1996.

ENJOLRAS, B. Gouvernance et intêret general dans les services sociaux et de santé. Bruxelles: CIRIEC/Peter Lang, 2008.

FARAH, M.F.S. ; BARBOZA, H.B. (Org.). Novas experiências de gestão pública e cidadania. Rio de Janeiro: FGV, 2001.

FERlie, E.; ASBurner, L.; FitzGerald, L. et al. A Nova Administração Pública em Ação. Brasília: Editora UNB/ENAP, 1999.

GAETANI, F. O ensino da administração Pública em um momento de inflexão. Revista do Serviço Público, v. 50, n. 4, p. 95-118, Out-Dez, 1999.

GARSON, G. D.; OVERMAN, S. Public Management Research in the United States. New York: Praeger Publishers, 1983.

GHON, M. G. Teoria dos Movimentos Sociais. Paradigmas Clássicos e Contemporâneos. São Paulo: Loyola, 2011.

GRAMSCI, A. La politica y lo Estado Moderno. Barcelona: Peninsula, 1971.

GULICK, L. Notes on the theory of organization In: GULICK, L; URWICK, L. (Org.). Papers on Science Administration. Nova York: Institute of Public Administration, p.1-46, 1937.

KAUFMAN, R. A política da reforma do Estado: um exame de abordagens teóricas. Revista do Serviço Público, Brasília: ENAP, v. 49, n. 1, p. 43-68, 1998.

KEINERT, T. M. M. Os paradigmas da administração pública no Brasil (1900-1992). Rev. Adm. Pública, v. 34, n. 3, p.41-48, 1994.

. Administração Pública no Brasil: crise e mudanças de paradigma. Annablume: FAPESP, 2000.

KETTL, D.F. A revolução global: reforma da administração do setor público. In: BRESSER PEREIRA. L. C. Reforma do Estado e Administração Pública Garencial. Rio de Janeiro: Editora da FGV, 2003.

KHUN, T. A estrutura das revoluções científicas. São Paulo: Perspectiva, 1987.

KOOIMAN, J. (Ed.). Modern Governance. Londres: Sage, 1993.

LINDBlOM, C. The Science of Muddling Through. Public Administration Review, v. 19, p. 79-88, primavera, 1959.

LIPIETZ, A. Audácia: uma alternativa para o século XXI. São Paulo: Nobel, 1991.

MARCH, J.; OLSEN, J. Democratic Governance. New York, The Free Press, 1995.

MARShall, G. The State of Public Management. Public Administration Review, v. 58, 1998.

MARSHALL, M. J. Citizen participation and the neighborhood context: a new look at the coproduction of local public goods. Political Research Quarterly, v. 57, n. 2, p. 231-244, june 2004. 
MENEGHETTI, F.K. Pragmatismo e os pragmáticos nos estudos organizacionais. Cad. EBAPE.BR, v. 5, n. 1, p. 1-13, 2007.

MILANI, C. R. S. O princípio da participação social na gestão de políticas públicas locais: uma análise de experiências latino-americanas e européias. Rev. Adm. Pública, v. 42, n. 3, p. 551-79, Maio/Jun de 2008.

MORGAN, G. Paradigmas, metáforas e resolução de quebra-cabeças na teoria das organizações. In: CALDAS, M; BERTERO, C. O. Teoria das Organizações. Série RAE Clássicos. São Paulo: FGV/RAE/Atlas, 2007.

MORIN, E.; Le MOIGNE, J.-L. L’inteligence de la complexité. Paris: l’Harmattan, 1999.

NADIR Jr., A. M.; SALM, J. F.; MENEGASSO, M. E. Estratégias e ações para a implementação do ICMS ecológico por meio da co-produção do bem público. Revista de Negócios, Blumenau, v.12, n.3, p. 62-73, julho/setembro, 2007.

NOGUEIRA, M. A. Um Estado para a sociedade civil. São Paulo: Cortez, 2005.

NUNES, E. O. A Gramática Política do Brasil. Clientelismo e insulamento burocrático. Rio de Janeiro: Zahar, 1997.

OFFE, C. New Social Mouvements: Challenging the Boundaries of Institutional Politics. Social Research, n.52, p. 81768, 1985.

OSBORN, D.; GAEBLER, E. Reinventing Government. Reading Mass: Addisson-Wesley, 1992.

OSTROM, E. An Agenda for the study of Institutions. Public Choice, v. 48, p. 3-25, 1986.

PAES DE PAULA, A.P. Por uma Nova Gestão Pública. Rio de Janeiro: FGV, 2005.

. Mauricio Tratenberg: contribuições de um marxista anarquizante para os estudos organizacionais críticos. Rev. Adm. Pública, v. 42, n. 5, p. 949-68, set/out, 2008.

POLLITT, C. Managerialism and Public Service. 2d ed. Cambridge: Bail Blackwell, 1993.

.; BOUCKAERT, G. Avaliando reformas da gestão pública: uma perspectiva internacional. Revista do Serviço Público, v. 53, n. 3, Jul-Set, 2002.

POUlantZAS, N. Poder Político e Classes Sociais. São Paulo: Martin Fontes, 1977.

. O Estado, o poder, o socialismo. Rio de Janeiro: Graal, 1981.

RAMOS, A. G. Administração e Contexto Brasileiro. Rio de Janeiro: FGV, 1966.

. A Nova Ciência das Organizações. Rio de Janeiro: FGV, 1989.

SCHERER-WARREN I.; KRISCHKE, P. J. (Org.) Uma revolução no cotidiano? Os novos movimentos sociais na América do Sul. São Paulo: Brasiliense, 1987.

SÉGUIN, F. ; CHANLAT, J.-F. L'analyse des organizations: une anthologie sociologique. Tome I. Les Theories des Organisations. Montreal: Gaetan Morin, 1992.

SERVA, M.; DIAS, T.; ALPERSTEDT, G. O paradigma da complexidade e a teoria das organizações: uma reflexão epistemológica. Revista de Administração de Empresas, v. 50, p. 276-287, 2010.

SIMON, H. A. The administrative behavior. Nova York: Macmillan, 1957.

SOUSA SANTOS, B. Um discurso sobre as ciências. Porto: Edições Afrontamento, 1988. 
. Democratizar a democracia: os caminhos da democracia participativa. Rio de Janeiro: Civilização Brasileira,

Conhecimento prudente para uma vida decente. Um discurso sobre as ciências revisitado. Porto: Edições Afrontamento, 2003.

TELLES, V. S. Movimentos sociais: reflexões sobre a experiência dos anos 70. In: SCHERER-WARREN I.; KRISCHKE P. J. (Org.). Uma revolução no cotidiano? Os novos movimentos sociais na América do Sul. São Paulo: Brasiliense, 1987.

WALDO, D. The Administrative State. Nova York, Ronald Press, 1948.

WEBER, M. L'etique protestante et l'esprit du capitalisme. Paris: Plon, 1964.

. Économie et société. Paris: Plon, 1971.

WhITAKeR, G. P. Coproduction: Citizen Participation in Service Delivery. Public Administration Review, p. 240246, Maio-Junho, 1980.

WHITE, L. D. Introduction to the study of public administration. Nova York: Macmillan, 1948.

WILLIAMSON, O. The Economic Institutions of Capitalism: Firms, Markets, Relational Contracting. New York: The Free Press, 1985.

WILSON, W. The study of Administration. Political Science Quartely, v.2, p.197-222, jun.1887. 